\title{
The Comparative Effect of Collaborative Strategic Reading and Content-Based Instruction on EFL Learners' Reading Comprehension
}

\author{
Mania Nosratinia (Corresponding author) \\ Islamic Azad University, Central Tehran Branch, Iran \\ E-mail: mania_nosratinia@yahoo.com \\ Negin Hooshmand Fateh \\ Islamic Azad University, Central Tehran Branch, Iran
}

Received: 24-04-2017

Published: 01-11-2017
Accepted: 16-06-2017

doi:10.7575/aiac.ijalel.v.6n.6p.165
Advance Access Published: September 2017

URL: http://dx.doi.org/10.7575/aiac.ijalel.v.6n.6p.165

\begin{abstract}
The present study was an attempt to compare the effect of teaching Collaborative Strategic Reading (CSR) and ContentBased Instruction (CBI) on the reading comprehension of English as a Foreign Language (EFL) learners. To fullfill this objective, a group of 90 intermediate female EFL learners, within the age range of 17 to 19 , took a piloted sample of the PET as a pre-treatment proficiency test. Sixty of them were selected as homogeneous learners and were randomly divided into two experimental groups of CSR and CBI. The CSR group receieved CSR strategy training based on Klingner, Vaughan, and Schumm's model (2001), while the CBI group receieved CBI-based strategy training, using Tsai and Shang's (2010) model. At the end of the training, another piloted PET reading test was administered as the posttest. The pre-treatment reading scores were analyzed using the Mann-Whitney $U$ test whose results confirmed the pre-treatment homogeneity of the participants. The post-treatment scores were also analyzed using the Mann-Whitney $\mathrm{U}$ test whose results indicated no significant difference in the reading posttest levels of CBI and CSR groups, $U=423.5$, $z=-.401, p=.688, r=-.0517$. The article concludes with a discussion on the results and presenting some implications.
\end{abstract}

Keywords: collaborative strategic reading, content-based instruction, reading comprehension, strategy training

\section{Introduction}

Reading, functioning as a major channel for receiving information, is now widely believed to be one of the most necessary and vital language skills (Lightbown \& Spada, 2013; Nosratinia, Mirzakhani \& Zaker, 2013), and testing reading comprehension is one of the measures for estimating the degree of pedagogical success, stated to be a valid measure for evaluating EFL learners' overall achievement (Harmer, 2007). Reading is a receptive skill, similar to listening, "during which readers decode the message of the writer and try to recreate it anew" (Rashtchi \& Keyvanfar, 2010 , p. 141), and the achievement of this goal enables the reader to engage in a real communication process in which the writer's intention is understood and the reader is able to integrate the new information into their cognitive structure (Anastasiou \& Griva, 2009).

ELT practice has always been intertwined with attempts in order to discover the components of reading comprehension and realize how L2 learners can master this skill (Erten \& Topkaya, 2009; Mitchell \& Myles, 2004). People might engage in reading for multiple purposes, e.g. for learning or for pleasure (Goodman, 1967); however, like other language skills, readers' involvement and cognitive engagement is of crucial importance in mastering this skill (Zaker, 2015), and it has been stated that "If the person is not aware of the text, not attending to it, not choosing to make meaning from it, or not giving cognitive effort to knowledge construction, little comprehension occurs" (Ozgungor \& Guthrie, 2004, p. 199). On the other hand, in the real life, reading comprehension is not developed without involvement in a social context, highlighting the role of social exchange and communication in the process of mastering this language skill (Zaker, 2016).

The complexity of learning processes in reading comprehension requires the instructors to pick up various means of teaching and assessment to gain the best results (Heron, 1988, as cited in Jafari Kardegar, 2014), and it seems that one of the effective means is using proper reading strategies (Pasquella, Gottardo, \& Grant, 2012). Oxford (1990) and Pasquella et al. (2012) believe that some effective strategies, skills, and assistant tools should be surveyed in order to facilitate the learners' reading ability. More specifically, strategy training is considered a highly effective pedagogical technique for enhancing reading comprehension (National Reading Panel, 2000). Moreover, research on reading development has shown that good readers use strategies that are not used by poor readers (Grabe \& Stoller, 2011). 
According to Oxford (1990), strategies are some techniques, mostly used by adult learners, which assist the readers in carrying out pedagogical and real-world tasks. Among them Collaborative Strategic Reading (CSR) is a set of instructional strategies to improve the reading comprehension of students with diverse abilities (Klingner \& Vaughn, 2000). CSR has been designed to facilitate reading comprehension for students who have different reading problems (Klingner \&Vaughn, 2000), and it is a useful strategy which employs explicit strategy instruction to improve students' reading comprehension (Hitchcock, Dimino, Kurdi, Wilkins, \& Gersten, 2011).

The strategies included in CSR practice are: (a) preview, (b) click \& clunk, (c) get the gist, and (d) wrap-up (Vaughn \& Klingner, 2000). Preview, happening before reading actually begins, intends to kindle readers' interest in reading, to activate their background knowledge, and make them more focused. Click and clunk, taking place during the reading process, intends to enable the readers to monitor their own reading performance. Get the gist, also happening during the reading process, aims to enable the reader to determine the main idea. Finally, wrap-up, as a post-reading activity, intends to enable the reader to review what they have read and review their understanding.

Besides CSR, since the early 1990s, the popularity and applicability of Content-Based Instruction (CBI) as a strategy which can be used to develop the process of reading among EFL learners has increased (Stoller, 2002). This strategy, in which cooperative learning is also incorporated (Crandall, 1993, as cited in Duenas, 2004), is one of the best realistic strategies for promoting the development of strategic learners within a language-learning curriculum (Grabe \& Stoller, 1997, as cited in Pessoa, Henry, \& Donato, 2007). CBI has been stated to encourage the development of the strategic language for the curricular developers (Leave \& Stryker, 1989, as cited in Duenas, 2004). Moreover, by using CBI strategy, learners may be able to construct knowledge through a wide range of ways which may lead them to be more independent readers (Barfield, 2003, as cited in Balcikanli, 2010).

Considering the abovementioned premises, it seems reasonable to consider CBI a useful tool for developing EFL learners' reading comprehension. However, considering the limitation and practical issues in English Language Teaching (ELT) contexts, it seems to be of outmost importance to draw a comparison among the available set of strategies for developing reading comprehension among EFL learners. Hoping to address this concern, the present study attempted to scrutinize the comparative effect of CSR and CBI on reading comprehension of EFL learners. To fulfill this purpose, the following research question was formulated:

Research Question: Is there any significant difference between the effect of CSR and CBI on EFL learners' reading comprehension?

\section{Method}

\subsection{Participants}

The main participants of this study were 60 female EFL learners within the age range of 17 to 19 who studied English as a foreign language at intermediate level in Iran Language Institute which is located in Tehran, Iran. These participants were non-randomly selected and homogenized from among 90 students through employing the Preliminary English Test (PET). The participants whose scores fell within one standard deviation below and above the mean were selected. They were randomly assigned into two experimental groups of 30 named CSR and CBI. Moreover, besides these individuals, a group of 30 students with almost similar characteristics to the target sample were used for the piloting of PET and reading posttest. Furthermore, besides one of the researchers as a teacher and rater, another trained rater attended the scoring of writing section of PET based on the General Mark Schemes for Writing.

\subsection{Instrumentation}

In order to come up with a satisfactory answer to the research question, the researchers employed some tests and the instructional material. The descriptions of these instruments are as follows:

\subsubsection{The Tests}

In order to homogenize the language proficiency of the students, the researchers administered a version of PET. It covers all four language skills -reading, writing, listening and speaking- and knowledge of grammar, vocabulary, and pronunciation. However, it should be noted that the speaking part of the test was not administered because of the practical issues and not having permission from institute officials to perform this part. To ensure that the two groups were homogeneous in terms of their reading ability, the scores of the reading section of PET were analyzed in isolation and were used as the pretest scores of the participants. Moreover, another piloted reading section of the PET was administered to the participants in the two experimental groups to estimate their reading comprehension at the end of the treatment phase.

\subsubsection{The Instructional Material}

The main textbook employed in both of the experimental groups during the instruction was Active Reading 3 (3rd ed.) by Anderson (2008), published by Asia and Global ELT. This book covers all the language skills of listening, speaking, reading, and writing with a focus on pronunciation, grammar and vocabulary. This book contains 12 units. In this study, the students during an eight-week term dealt with eight units (unit one to eight) whose topics were "Travel", " Fashion", "Disappearing Animals", "Big Money", " Celebrations Around the World", "It's a Mystery", "Health and Fitness" and "Space and Flight" respectively. 


\subsection{Procedure}

To conduct the research, the following steps were taken:

After having the homogenized learners (as explained above), they were divided into two experimental groups, namely CSR and CBI on a random basis, each group containing 30 participants. The two groups were instructed by the same teacher (one of the researchers), using the same material. The teacher (one of the researchers) tried to teach the relevant grammatical points as well as the essential vocabularies alongside the language skills with special focus on the reading skill. The only difference lay in teaching of CSR to one group and implementing CBI to the other group.

Both of the experimental groups attended their classes twice a week for 16 sessions during eight weeks. Each session took about 90 minutes. The time of the class was divided into two parts. The first part lasted 55 minutes. During this part, the course book was taught to both of the experimental groups in the same way except the reading comprehension sections. After a five-minute break, the second part, which lasted for 30 minutes, was devoted to the treatment of reading comprehension sections. This part was different in two experimental groups. The following section clarifies the step by step procedure being performed in each group.

\subsubsection{Collaborative Strategic Reading (CSR)}

In this group, the reading passages in the textbook were taught step by step using CSR strategy based on Klingner et al.'s model (2001). The teacher explicitly taught the CSR strategies through four sessions. Each strategy was presented by giving examples. According to Klingner et al. (2001), in CSR, students learn four strategies: (a) preview (before reading), (b) click \& clunk (during reading), (c) get the gist (during reading), and (d) wrap-up (after reading). The implementation of the strategies was described as follows:

Preview

Preview is a strategy to activate students' prior knowledge, to facilitate their predictions about what they will read, and to generate interest. Preview consists of two activities: (a) brainstorming and (b) making predictions. It is used only before reading of the text. Here, the teacher asked students to skim information such as headings, pictures, and words that are bolded or underlined in order to brainstorm what they already know about the topic and predict ideas they might learn from the text. In this part, the students should write their brainstormed ideas and predictions about what they might learn, in their learning logs.

\section{Click-and-Clunk}

Click and clunk is a strategy that teaches students to monitor their understanding during reading, and to use fix-up strategies when they realize their failure to understand text. The teacher described that clicks refer to parts of the text that you really get and clunks are those words, concepts or ideas that you really don't understand. Then, the teacher read a short piece of reading text aloud and asked the students to record clunks in their learning logs. Students then work together, using fix-up strategies to discover what their clunks mean.

\section{Get the Gist}

Get the gist is a strategy to help students identify main ideas during reading. The goal of getting the gist is to teach students to restate the most important points in their own words, to make sure that they have understood what they have read. The participants in CSR group were expected to write out the gist for each paragraph in ten words or less. This was then completed for each of the paragraphs and then they worked in groups to compare their gist, for each individual paragraph. In order to identify the main idea, the participants were asked to answer these questions:

- What is the most important person, place, or thing?

- What is the most important idea about the person, place, or thing?

\section{Wrap Up}

The goals of this strategy are to improve the students' knowledge, understanding, and memory of what they have read. Wrap up consists of two activities: generating questions and reviewing. The teacher suggested the following question starters: who, what, when, where, why, and how. The teacher also encouraged students to generate questions that ask about important information in the passage they had just read. Furthermore, the participants were invited to think of questions they would ask if they were the teacher (pretend as if they were teacher) to find out if their students really understood what they had read. Other students had to try to answer their peer's questions.

\subsubsection{Content-Based Instruction (CBI)}

In this experimental group, reading passages were taught through using the CBI framework proposed by Tsai and Shang (2010). Tsai and Shang (2010) basically proposed a set of steps for attempting to develop EFL learners' reading comprehension in CBI courses. This is to say that this framework is proposed for EFL courses in which the focus is on the content of the texts, and learners are mainly required to learn about the general meaning and the order of stated points and are finally able to re-write/re-state what they have read in their own words. In this regard, at the beginning of the course, the participants in the CBI group were informed that their performance was going to be assessed based on what they learn from each topic not necessarily the words and structures presented. Through this briefing to the course, the teacher provided some example questions, basically inferential and content questions, in order to clarify the issue further. During each session the framework proposed by Tsai and Shang (2010) was followed whose sections are stated hereunder: 


\section{Pre-Reading Stage}

The purpose of this stage was to stimulate students' interests through identifying their background knowledge and incorporating it into new information. Activities such as prediction in which the students predicted the content based on the title were used at this stage.

\section{During-Reading Stage}

At this stage, the focus was on helping students to be aware of the meaning of the text. The following activities were employed for this purpose:

- Parsing exercise: The teacher parsed complicated sentences in each text into simple sentences. This way, the students could find different types of cues to find the meaning of unfamiliar words.

- Scrambling exercise: The teacher extracted some segments from each text, cut each section into pieces, and then asked students to put the scrambled sentences in the right order.

\section{Post-Reading Stage}

As stated by Tsai and Shang (2010), at this stage, students would try out new knowledge and practice new skills, supported by the teacher and peer feedback. Tsai and Shang (2010) further recommended using activities such as watching a movie and role-playing. However, considering the time and institutional limitations, the teacher used roleplays and summary writing activities after each reading segment. More specifically, after finishing the during-reading phase, learners were asked to engage in role plays and have a discussion with their partners on the issue presented in each reading segment. Furthermore, the participants were asked to write down the summary of the text, using their own words and structures. They were informed that the summaries collected by the teacher would be evaluated regarding inclusion of main points in the text and exhibiting reasonable knowledge about the topic. The teacher returned the summaries in the following section with some comments and feedbacks.

\section{Results}

\subsection{Checking the Pre-Treatment Homogeneity of the Participants}

The scores of the reading section of the homogenization PET test were considered the pretest scores of the study (Table 1). The obtained scores of the participants in the experimental groups were to be analyzed/compared through running an independent samples $t$-test. However, prior to running this test, it was needed to assess the normality of the data in the two groups separately. To do so, the Kolmogorov-Smirnov test was run results of which are reported in Table 2.

Table 1. Descriptive Statistics for Reading Pretest Scores

\begin{tabular}{llcccc}
\hline & Treatment & N & Mean & Std. Deviation & Std. Error Mean \\
\hline Reading Pretest & CBI & 30 & 18.0333 & 4.25468 & .77679 \\
& CSR & 30 & 18.2667 & 3.71329 & .67795 \\
\hline
\end{tabular}

Table 2. Test of Normality on the Pretest Scores in the Two Groups

\begin{tabular}{llccccccc}
\hline & & \multicolumn{3}{c}{ Kolmogorov-Smirnova $^{\mathrm{a}}$} & \multicolumn{3}{c}{ Shapiro-Wilk } \\
\cline { 3 - 8 } & Treatment & Statistic & $\mathrm{df}$ & Sig. & Statistic & df & Sig. \\
\hline Reading Pretest & CBI & .189 & 30 & .008 & .935 & 30 & .066 \\
& CSR & .154 & 30 & .069 & .959 & 30 & .291 \\
\hline
\end{tabular}

a. Lilliefors Significance Correction

As reported in Table 2, the Sig. value for the CBI group is smaller than the .05 cut-point (.008). Therefore, the normality of distribution for the CBI group was not confirmed. As a result, the non-parametric alternative to the independent-samples $t$-test, the Mann-Whitney $\mathrm{U}$ test was employed for checking the pre-treatment homogeneity of the participants. Table 3 through Table 5 report the results.

Table 3. The Table of Ranks for the Pretest Scores

\begin{tabular}{lllcc}
\hline & Treatment & N & Mean Rank & Sum of Ranks \\
\hline Reading Pretest & CBI & 30 & 30.03 & 901.00 \\
& CSR & 30 & 30.97 & 929.00 \\
& Total & 60 & & \\
\hline
\end{tabular}


Table 4. the Median Scores for the Groups on the Pretest

Reading Pretest

\begin{tabular}{lll}
\hline Treatment & $\mathrm{N}$ & Median \\
\hline CBI & 30 & 18.0000 \\
CSR & 30 & 18.0000 \\
Total & 60 & 18.0000 \\
\hline
\end{tabular}

Table 5. Mann-Whitney U Test on Pretest Scores

\begin{tabular}{lc}
\hline & Reading Pretest \\
\hline Mann-Whitney U & 436.000 \\
Wilcoxon W & 901.000 \\
Z & -.208 \\
Asymp. Sig. (2-tailed) & .835 \\
\hline
\end{tabular}

a. Grouping Variable: Treatment

As reported in Table 5, the Mann-Whitney $\mathrm{U}$ test revealed no significant difference in reading pretest levels of CBI ( $M d$ $=18, n=30)$ and CSR $(M d=18, n=30) . U=436, z=-.208, p=.835, r=-.0268$ (representing a very small effect size). Therefore, the pretreatment homogeneity of the participants regarding reading comprehension was confirmed. Based on the obtained results in this section, it was concluded that the participants in the two experimental groups demonstrated the same quality in reading comprehension. As a result, the subsequent potential score differences could be assumed pertinent to the treatments.

\subsection{Checking the Assumption of Normality}

According to Tabachnick and Fidell (2007), when the sample size is larger than 30, the violation of the assumption of normality would not cause any major problem. Nevertheless, in order to inspect the normality of the data, the posttest data were analyzed using the Kolmogorov-Smirnov test, results of which are reported in Table 6.

Table 6. Test of Normality on the Posttest Scores in the Two Groups

\begin{tabular}{llcccccc}
\hline & & \multicolumn{3}{c}{ Kolmogorov-Smirnov $^{\mathrm{a}}$} & \multicolumn{3}{c}{ Shapiro-Wilk } \\
\cline { 2 - 8 } & Treatment & Statistic & $\mathrm{df}$ & Sig. & Statistic & $\mathrm{df}$ & Sig. \\
\hline Reading Posttest & CBI & .223 & 30 & .001 & .920 & 30 & .026 \\
& CSR & .201 & 30 & .003 & .921 & 30 & .028 \\
\hline
\end{tabular}

a. Lilliefors Significance Correction

As reported in Table 6 , the Sig. values for the two groups are smaller than the .05 cut-point (.001 \& .003). Therefore, the normality of distribution for the two groups was not confirmed. As a result, the non-parametric alternative to the independent-samples $t$-test, the Mann-Whitney $\mathrm{U}$ test had to be employed for answering the research question.

\subsection{Answering the Research Question}

As mentioned above, in order to accomplish the purpose of this study, one research question was framed. Based on the design of the study and the characteristics of the variables, the researcher initially opted for an independent-samples $t$ test. However, as stated above, the normality of distribution for the two groups on the posttest was not confirmed. As a result, the non-parametric alternative to the independent-samples $t$-test, the Mann-Whitney $\mathrm{U}$ test was employed for answering the research question. Table 7 through Table 10 report the results.

Table 7. Descriptive Statistics for Reading Posttest Scores

\begin{tabular}{llcccc}
\hline & & & Std. & \\
& Treatment & N & Mean & Deviation & Std. Error Mean \\
\hline Reading Posttest & CBI & 30 & 32.1667 & 1.68325 & .30732 \\
& CSR & 30 & 32.0000 & 1.89373 & .34575 \\
\hline
\end{tabular}


Table 8. The Table of Ranks for the Posttest Scores

\begin{tabular}{lllcc}
\hline & Treatment & N & Mean Rank & Sum of Ranks \\
\hline Reading Posttest & CBI & 30 & 31.38 & 941.50 \\
& CSR & 30 & 29.62 & 888.50 \\
& Total & 60 & & \\
\hline
\end{tabular}

Table 9. The Median Scores for the Groups on the Posttest

\begin{tabular}{lll}
\multicolumn{3}{c}{ Reading Posttest } \\
\hline Treatment & $\mathrm{N}$ & Median \\
\hline CBI & 30 & 32.0000 \\
CSR & 30 & 31.5000 \\
Total & 60 & 32.0000 \\
\hline
\end{tabular}

Table 10. Mann-Whitney U Test on Posttest Scores

\begin{tabular}{lc}
\hline & $\begin{array}{c}\text { Reading } \\
\text { Posttest }\end{array}$ \\
\hline Mann-Whitney U & 423.500 \\
Wilcoxon W & 888.500 \\
Z & -.401 \\
Asymp. Sig. (2-tailed) & .688 \\
\hline a. Grouping Variable: Treatment
\end{tabular}

a. Grouping Variable: Treatment

As reported in Table 10, the Mann-Whitney $\mathrm{U}$ test revealed no significant difference in reading posttest levels of CBI $(M d=32, n=30)$ and CSR $(M d=31.5, n=30)$ groups, $U=423.5, z=-.401, p=.688, r=-.0517$ (representing a very small effect size). Figure 1 demonstrates the reading mean scores of the participants in the two experimental groups, before and after receiving the treatment. As illustrated, the results suggest significant effect of these two strategies on EFL learners' reading comprehension.

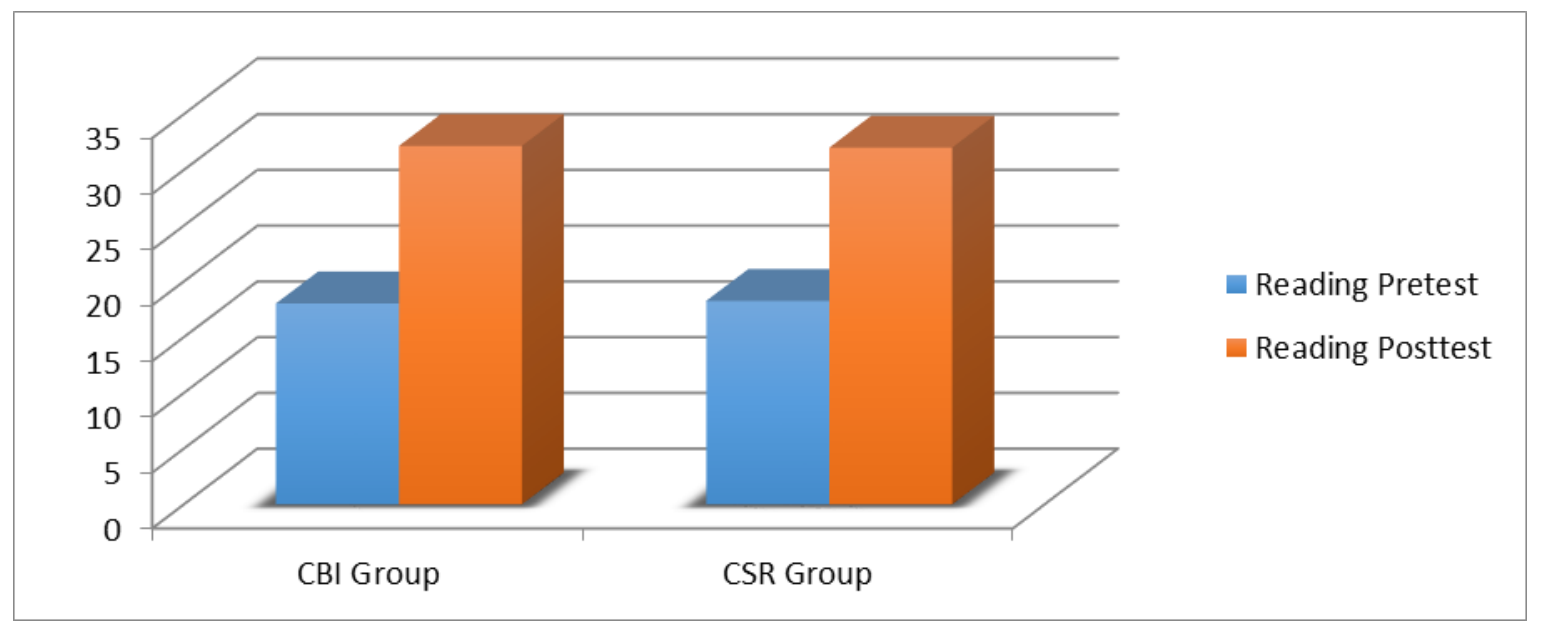

Figure 1. Pretest and posttest scores in the two experimental groups

\section{Discussion}

Among the different components of language proficiency, reading, functioning as a major channel for receiving information, has always been connected with knowledge acquisition, maturation of thoughts, and advancement (Harmer, 2007). Reading can be considered a conversation between the reader and the writer in which either the original message or a personal interpretation based on the text is acquired by the reader (Grabe, 2009). Regarding the pedagogical concerns, testing reading comprehension is one of the measures for estimating the degree of pedagogical success, stated to be a valid measure for evaluating EFL learners' achievement (Harmer, 2007). Consequently, ELT practice has always been intertwined with attempts in order to discover the components of reading comprehension and realize how L2 learners can master this skill (Mitchell \& Myles, 2004).

Besides linguistic knowledge, topic familiarity, and general experience, the cognitive skills readers possess and use are assumed to significantly correlate with their reading comprehension in general (Anastasiou \& Griva, 2009). Based on 
this premise, ELT programs are now encouraging the use of strategies in mastering language skills, including reading comprehension (Oxford, 1990). In a similar vein, ELT textbooks now include strategy use for developing reading comprehension (Lehr \& Osborn, 2005). Among the strategies applicable to reading, CSR and CBI have been gaining considerable popularity in the ELT domain (Klingner \&Vaughn, 2000; Stoller, 2002).

Rooted in the premises stated above, this study attempted to compare the impact of CBI and CSR on EFL learners' reading comprehension. After instructing two homogenous groups on using CBI and CSR strategies, the post-treatment reading performance of the participants were to be analyzed running an independent-samples $t$-test. However, as stated above, the normality of distribution for the two groups on the posttest was not confirmed. Therefore, the non-parametric alternative to the independent-samples $t$-test, the Mann-Whitney $\mathrm{U}$ test, was employed for answering the research question. As reported in Table 10, the Mann-Whitney $\mathrm{U}$ test revealed no significant difference in reading posttest levels of CBI $(M d=32, n=30)$ and CSR $(M d=31.5, n=30)$ groups, $U=423.5, z=-.401, p=.688, r=-.0517$ (representing a very small effect size).

The obtained results, stated above, indicate that the post-treatment reading performance of the participants after receiving CBI and CSR in the two experimental groups have been similar. This is to say that CBI and CSR have a similar impact on EFL learners' reading comprehension. There have been numerous studies separately confirming the positive and significant impact of CSR (Katims \& Harmen, 2009; Nosratinia et al., 2013) and CBI (Andrade \& Makaafi, 2001; Yiyu, 2014) on developing reading comprehension among EFL learners. However, no previous study has compared CBI and CSR in an EFL context while focusing on reading comprehension. Therefore, the results of this study could not be compared with those obtained from other studies.

Although previous research has confirmed the significant contribution of CBI and CSR to reading comprehension, these two strategic frameworks do not necessarily recommend similar goals and focuses, the former focusing on mastering the specific content while the latter focusing on developing reading skills in general. One of the reasons for obtaining similar results out of these two treatments could be the fact that developing language skills, including reading comprehension, is significantly affected by language learners' unique peculiarities (Lightbown \& Spada, 2013; Nosratinia \& Zaker, 2014, 2015). Moreover, as stated by Taguchi (2004), background knowledge plays an important role in constructing meaning from texts. Therefore, the similar results in the two experimental groups might have been resulted from participants' personal differences and different backgrounds, not the treatments on their own. As a result, CBI and CSR frameworks can be both cognitively profitable and pedagogically effective.

\section{Conclusion}

In foreign language teaching, reading can be considered the most important skill needed to be honed (Susser \& Rob, 1990, as cited in Alyas, 2012). On the other hand, there are many ways to improve and enhance the process of reading comprehension among students. One of the useful ways is using strategies in English classes. As Oxford (1990) argues, some effective strategies, skills, and assistant tools should be surveyed in order to facilitate the learners' reading abilities. In other words, poor readers are those who are not well aware of effective strategies, as a result they are not good readers (Nokhbeh Rousta \& Ghazi Mirsaeed, 2012).

This study was mainly motivated by the desire to highlight the significance of strategies in language teaching and study the way the new developments in this area can facilitate and promote the process of reading comprehension. Hoping to address the above mentioned concern, the present study aimed at exploring the comparative effect of CSR and CBI on EFL learners' reading comprehension. CSR, being a strategic framework, has been defined as "an instructional practice designed to facilitate reading comprehension" (Klingner et al., 2001, p. 88). On the other hand, CBI is a pedagogic framework in which "the language becomes the medium through which something new is learned" (Stoller, 2002, p. 109).

There have been numerous studies separately confirming the positive and significant impact of CSR (Katims \& Harmen, 2009; Nosratinia et al., 2013) and CBI (Andrade \& Makaafi, 2001; Yiyu, 2014) on developing reading comprehension among EFL learners. However, no previous study has compared CBI with CSR, a strategic framework with a pedagogic framework, in an EFL context while focusing on reading comprehension. Consequently, such a comparison will enable EFL practitioners to come up with a more comprehensible understanding of teaching reading, the appropriateness of the material, and the options available to the teachers when they are limited to using specific textbooks.

Based on the abovementioned premises, this quasi-experimental study, with a comparison group and posttest-only design, regarded the type of training, CSR or CBI, as the independent variable and reading comprehension as the dependent variable. Comparing the reading performance of the homogenous participants after the treatment phase came to an end revealed that CSR and CBI, as implemented in this study, have a similar effect on EFL learners' reading comprehension. This is to say that CBI can be as useful as CSR if the pedagogical practice highlights the value of cooperation, overall comprehension, and previewing and predicting. Therefore, it seems that EFL teachers can use both CSR and CBI to make learners have a higher level of reading comprehension.

According to Stones (2002, as cited in Nosratinia et al., 2013), if teachers intend to have effective teaching and reasonable outcome, they need to go one step beyond the simple and ordinary instructions and processes usually done in the classroom. Their success mostly depends on their applications of the strategies to develop the learners' understanding of what they have been exposed to. Familiarity with strategies and properly exploiting them could be 
beneficial in all teaching domains. As Oxford (1990) believed strategies are foundations to the effective teaching of any subject, and it must be at the heart of any professional development program.

The results of the present study indicated that CSR and CBI can have similar significant effects on EFL learners' reading comprehension provided that the CBI-based framework for reading as offered by Tsai and Shang (2010) is implemented. Consequently, EFL teachers are recommended to attempt to study the CBI-based framework of Tsai and Shang (2010) and the CSR model of Klingner et al. (2001) for instructing reading. More importantly, EFL teachers should focus on the similarities the two abovementioned reading instruction models share. This is to say that EFL teachers should:

- attempt to relate the new material to readers' background knowledge and enable then to make predictions before going through reading activities,

- focus on developing learners' overall understanding of the text through employing inferential questions and skimming tasks, and

- employ cooperative activities and engage learners in group activities.

EFL teachers are also recommended to elaborate on the advantages of active participation in reading activities and, simultaneously, provide positive feedback and reinforcement when EFL learners demonstrate an acceptable level of engagement in group activities. Finally, as it is the case with many other pedagogical tasks, EFL teachers should create an environment in which EFL learners feel comfortable and confident to participate in pedagogical tasks and, in this case, carry out the reading tasks with a lower level of anxiety and a higher level of concentration.

The current TEFL paradigm considers a major role for EFL learners where they are expected to actively engage in learning activities (Mitchell \& Myles, 2004). Consequently, EFL learners should internalize the idea that active engagement in learning activities plays a key role in developing L2 proficiency. This premise is quite pertinent to the findings of the present study in which CBI turned out to be as pedagogically effective as CSR. The significance of cooperation and active engagement in learning becomes more evident when the CBI and CSR models of Tsai and Shang (2010) and Klingner et al. (2001) are compared. Based on this comparison and rooted in the findings of the present study, EFL learners are recommended to:

- try to establish a link between the texts and their own background knowledge through a reflective process,

- try to make predictions about the stated points before going through reading activities,

- try to improve their overall understanding of the text through observing the text and employing skimming,

- engage in cooperative activities and share their understanding of the text afterwards, and

- employ the strategies proposed with Tsai and Shang (2010), pre-reading, during-reading, and post-reading, when doing extensive reading or studying different topics in their daily lives.

Based on the findings of the present study, a statistically-supported justification is provided for the integration of cooperative reading tasks in ELT materials and textbooks. Syllabus designers and material developers are also recommended to present strategy training sections in which EFL learners are encouraged to:

- establish a link between the texts and their own background knowledge through a reflective process,

- make predictions about the stated points before going through reading activities,

- improve their overall understanding of the text through observing the text and employing skimming,

- engage in cooperative activities and share their understanding of the text afterwards, and

- employ the strategies proposed with Tsai and Shang (2010), pre-reading, during-reading, and post-reading, when doing extensive reading or studying different topics in their daily lives.

A number of recommendations are presented here, hoping that other researchers would find them interesting enough to pursue in the future.

1. This study was conducted among EFL learners, within the age range of 17 and 19 years old $\left(M_{\text {age }}=18\right)$. The same study could be conducted among other age groups, making it possible to inspect the way age interacts with the implementation of CBI and CSR.

2. The present study was conducted on female EFL learners. Therefore, further investigations can include both male and females.

3. Other studies can replicate this study in a way that the CBI group is only exposed to one specific topic in the reading tasks.

4. The time allotted to working on reading in both of the groups was 30 minutes in 16 sessions. Other studies can allot a longer period of time to see if this modification can affect the results.

5. As language learners' language skills are believed to significantly correlate with their mental capacities, other studies are recommended to inspect the pre-treatment state of these factors and the way they are affected by the treatments.

6. Other studies can supplement the obtained data by using qualitative measures, e.g. interviews and observation.

\section{References}

Alyas, A. (2012). Metacognitive strategies and learner autonomy in EFL reading. Retrieved March 23, 2015, from: https://www.mjltm.com/indext

Anastasiou, D., \& Griva, E. (2009). Awareness of reading strategy and reading comprehension among poor and good readers. Elementary Education Online, 8(2), 283-297. 
Andrade, M. S., \& Makaafi, J. H. (2001). Guidelines for establishing adjunct courses at the university level. TESOL, 10 (213), 33-39.

Balçıkanlı, C. (2010). Learner autonomy in language learning: Student teachers' beliefs. Australian Journal of Teacher Education, 35(1). Retrieved March 24, 2016, from: http://dx.doi.org/10.14221/ajte.2010v35n1.8

Duenas, M. (2004). The whats, whys, hows and hows of content-based instruction in second/foreign language education. Espinardo, 4(1), 73-96.

Erten, I. H., \& Topkaya, E. Z. (2009). Understanding tolerance of ambiguity of EFL learners in reading classes at tertiary level. Novitas-ROYAL, 3(1), 29-44.

Goodman, K. (1967). Analysis of reading miscues: Applied psycholinguistics. In J. Samuels \& M. A. Kamil (Eds.), Handbook of reading research (pp. 186-198). New York: Longman.

Grabe, W. (2009). Reading in a second language: Moving from theory to practice. Cambridge: Cambridge University Press.

Grabe, W., \& Stoller, F. (2011). Teaching and researching reading (2nd ed.). Harlow, UK: Pearson Longman.

Harmer, J. (2007). The practice of English language teaching (4th ed.). Harlow: Longman.

Hitchcock, J., Dimino, J., Kurki, A., Wilkins, C., \& Gersten, R. (2011). The impact of Collaborative Strategic Reading on the reading comprehension of grade 5 students in linguistically diverse schools. Washington, DC: Department of Education.

Jafari Kardegar, L. (2014). The comparative effect of portfolio, peer, and self- assessment on EFL learners' reading comprehension (Unpublished master's thesis). Islamic Azad University at Central Tehran, Iran.

Katims, D. S., \& Harmon, J. M. (2000). Strategic instruction in middle school social studies: Enhancing academic and literary outcomes for at-risk students. Intervention in School and Clinic, 33(5), 28-89.

Klingner, J. K. Vaughn, S., \& Schumm, J. S. (2001). Collaborative strategic reading during social studies in heterogeneous fourth grade classrooms. Elementary School Journal. 2(5), 123-45.

Klingner, J. K., \& Vaughn, S. (2000).The helping behaviors of fifth graders while using collaborative strategic reading during ESL content classes. TESOL Quarterly, 34(1), 69-98.

Lehr, F., \& Osborn, J. (2005). Focus on reading comprehension. Retrieved June 17, 2015, from www.prel.org/programs/rel/rel.asp

Lightbown, P., \& Spada, N. (2013). How languages are learned (4th ed.). Oxford: Oxford University Press.

Mitchell, R., \& Myles, F. (2004). Second language learning theories (2nd ed.). London: Edward Arnold.

National Reading Panel. (2000). Teaching children to read: An evidence-based assessment of the scientific research literature on reading and its implications for reading instruction. Washington, DC: National Institute of Child Health and Human Development and U.S. Department of Education.

Nokhbeh Rousta, S., \& Ghazi Mirsaeed, S. J. (2012).The effect of teaching metacognitive reading strategies on reading self-efficacy of Iranian intermediate EFL students. Journal of Academic and Applied Studies, 2(11), 10-20.

Nosratinia, M., Mirzakhani, E., \& Zaker, A. (2013). Toward a humanistic instruction: Collaborative strategic approach and EFL learners' reading comprehension. International journal of Advanced Studies in Humanities and Social Science (IJASHSS), 1(8), 1119-1138.

Nosratinia, M., \& Zaker, A. (2014). Metacognitive attributes and liberated progress: The association among second language learners' critical thinking, creativity, and autonomy. SAGE Open, 4(3), 1-10. doi: $10.1177 / 2158244014547178$.

Nosratinia, M., \& Zaker, A. (2015). Boosting autonomous foreign language learning: Scrutinizing the role of creativity, critical thinking, and vocabulary learning strategies. International Journal of Applied Linguistics and English Literature, 4(4), 86-97. doi: 10.7575/aiac.ijalel.v.4n.4p.86

Oxford, R. L. (1990). Language learning strategies: What every teacher should know. Boston, Massachusetts: Heinle \& Heinle Publishers.

Ozgungor, S., \& Guthrie, J. T. (2004). Interactions among elaborative interrogation, knowledge, and interest in the process of constructing knowledge from text. Journal of Educational Psychology, 96, 437-443. doi: 10.1037/00220663.96.3.437

Pasquella, A., Gottardo, A., \& Grant, A. (2012). Comparing factors related to reading comprehension in adolescents who speak English as a first (L1) or second (L2) language. Scientific Studies of Reading, 16, 475-503.

Pessoa, S., Hendry, H., \& Donato, R. (2007). Content-based instruction in the foreign language classroom (Unpublished MA thesis) Pennsylvania State University, Pennsylvania, USA.

Rashtchi, M., \& A. Keyvanfar. (2010). ELT: Quick ' $n$ ' easy. Tehran: Rahnama Press.

Stoller, F. L. (2002). Promoting the acquisition of knowledge in a content-based course. In J. Crandall \& D. Kaufman (Eds.), Content-Based instruction in higher education settings (pp. 109-123). Alexandria, VA: TESOL.

Tsai, Y., \& Shang, H. (2010). The impact of content-based language instruction on EFL students' reading performance. Asian Social Science, 6(3), 77-85.

Yiyu, Z. (2014). Applying Content-Based Instruction to Extensive Reading Class. Studies in Literature and LanguageCS Canada, 9(1), 77-81.

Zaker, A. (2015). EFL learners' language learning strategies and autonomous learning: Which one is a better predictor of L2 skills? Journal of Applied Linguistics-Dubai, 1(1), 27-39.

Zaker, A. (2016). Social constructivism and metacognition in an EFL context: Inspecting the contribution of critical thinking to EFL learners' social intelligence. Humanising Language Teaching, 18(6). Retrieved from www.hltmag.co.uk/dec16/index.htm 